\title{
DIAGNÓSTICO ESPACIAL DA CONCENTRAÇÃO PRODUTIVA DO CAFÉ NO BRASIL, NO PERÍODO DE 1991 A $2003^{1}$
}

\author{
Rafael Morais de Souza ${ }^{2}$ \\ Fernando Salgueiro Perobelli ${ }^{3}$
}

\begin{abstract}
Resumo - Este trabalho objetivou estudar a distribuição espacial do café entre as 558 microrregiões brasileiras, no período de 1991 a 2003, ou seja, identificar regimes espaciais ou clusters desta commodity e sua dinâmica no decorrer dos anos em estudo. Para isto, foram utilizados o quociente locacional para medir a concentração da produção do café e a análise exploratória de dados espaciais. É possível destacar que a estrutura espacial de produção do café persiste espacialmente concentrada, principalmente nos estados de Minas Gerais e Espírito Santo, que, em 2004, contribuíram com 70,66\% da produção nacional do café, e em microrregiões do estado de Rondônia, que apresentaram quocientes locacionais muito elevados na produção desse produto.
\end{abstract}

Palavras-chave: análise exploratória de dados espaciais, café, base de exportação, quociente locacional.

Recebido em: 21/05/2007 Aceito em: 28/09/2007

${ }^{2}$ Mestrando em Economia Aplicada pela UFJF. E-mail: rmoraisjf@yahoo.com.br

3 Professor da UFJF. E-mail: fernando.perobelli@ufjf.edu.br 


\section{Introdução}

De acordo com Vale et al. (2006), o sistema agroindustrial do café tem sido estudado, exaustivamente, pelos pesquisadores (Santos et al., 2005; Rugani e Silveira, 2006; Gomes e Rosado, 2005). Segundo Gomes e Rosado (2005), a cafeicultura é uma atividade de grande importância para o cenário internacional e contribui, em larga escala, para a geração de emprego e de divisas no país. Tais fatores, por si só, justificariam os esforços de pesquisa para entender melhor tal cultura. Segundo Vale et al. (2006), a importância do café pode ser enfatizada por diferentes indicadores, dentre os quais se destacam: a) o movimento financeiro da cadeia mundial do café; b) o volume de exportações mundiais; c) a capacidade de geração de empregos; e d) a contribuição para o aumento da renda. Além destes fatores, faz-se mister destacar o papel desempenhado pela cafeicultura no processo de desenvolvimento econômico brasileiro, ou seja, como fonte de financiamento do crescimento da economia brasileira por meio da geração de divisas para o processo de industrialização do país.

Segundo Gomes e Rosado (2005), a atividade cafeeira apresenta grande potencial de crescimento tanto no mercado interno, devido, em grande parte, ao processo de estabilização, quanto no externo, devido ao processo de globalização. As autoras afirmam que o Brasil tem potencial para aumentar a produção em $10 \%$ ou $20 \%$ em um ano. Se isso ocorrer, o país tornar-se-á, novamente, um importante player da atividade cafeeira. Assim, o setor teria as condições necessárias para aumentar sua competitividade tanto no mercado interno quanto no externo. Tal processo poderia induzir à marginalização de muitos produtores e regiões, devido à profissionalização da atividade e à concentração desta em regiões mais favoráveis.

Em termos espaciais, os estados de Minas Gerais, Espírito Santo, São Paulo e Paraná são os maiores produtores da commodity, sendo Minas Gerais o maior produtor de café arábica e o Espírito Santo, o maior produtor de café conillon. É importante ressaltar que, mesmo nos estados 
anteriormente mencionados, há uma heterogeneidade espacial na produtividade e no uso de tecnologia (Rugani e Silveira, 2006).

Em face do exposto, este trabalho objetivou estudar a distribuição espacial da produção de café entre as 558 microrregiões brasileiras, no período de 1991 a $2003^{4}$, ou seja, identificar regimes espaciais ou clusters desta commodity e sua dinâmica no decorrer dos anos em estudo. Este trabalho contribui para o melhor entendimento da cultura cafeeira, pois trata a questão espacial desta à luz da teoria da base de exportação5. Assim, permite verificar o potencial local latente das microrregiões, no que se refere à produção cafeeira. Em outras palavras, busca diagnosticar o caráter espacial heterogêneo da base produtiva das microrregiões, enfatizando a importância da cultura (setor) no contexto nacional.

Cabe ainda ressaltar que a agricultura é muito suscetível às questões espaciais, pois, como é sabido, o desenvolvimento de culturas agrícolas (i.e., no presente trabalho café) é heterogêneo, já que depende de diferentes técnicas de produção, condições climáticas, solo e temperatura.

Este artigo está disposto, além desta introdução, da seguinte maneira: a) revisão da literatura; b) explanação da metodologia e do tratamento dos dados; c) análise dos resultados encontrados; e d) conclusão.

\section{Revisão de Literatura}

O processo de crescimento regional pode ser explicado por diversas correntes de pensamento econômico, dentre as quais se destaca a idéia de North (1977). Segundo esse autor, a exportação regional é o principal fator que determina o crescimento de uma região e, portanto, a interação de tal região com demais regiões (i.e., outras unidades da Federação,

\footnotetext{
Nos anos de 1990 e 2002, o consumo interno de café teve tendência sustentada de crescimento. No ano de 2003, houve um declínio, razão por que se optou por analisar o período recente, que compreende a expansão do consumo interno do café.

5 O indicador da base de exportação adotado neste trabalho será o Quociente Locacional. Esta medida está explicitada na seção 3 , deste trabalho.
} 
outras microrregiões e outros países). Assim, ao analisar uma região, faz-se necessário verificar as relações (i.e., fluxos de produtos e serviços, fluxos de capital e mão-de-obra) desta com as demais que compõem o sistema. Cabe ressaltar que tais fluxos ocorrem devido à especialização regional. A contribuição de Douglas North centra-se na idéia da base de exportação (North 1977).

Segundo Richardson (1973) e Fujita, Krugman e Venables (1999), ao observar a economia de determinada região, é plausível pensar que as atividades econômicas de uma região $(E)$ sejam divididas em dois tipos. Por um lado, existem atividades que satisfazem às demandas de fora da região, ou seja, a base de exportação da região $\left(E_{b}\right)$; por outro, existem atividades que são fornecedoras, principalmente, de produtos e serviços aos residentes locais $\left(E_{n b}\right)$. Cabe ressaltar que a divisão das atividades econômicas em dois componentes é um dos aspectos centrais do modelo de base econômica. Portanto,

$E_{t}=E_{b}+E_{n b}$.

Nas aplicações do modelo, $E_{t}$ pode ser representado pelo nível de emprego (ou produção) total na região ou pelo nível de renda regional. Já $E_{b}$ é medido pelo nível de emprego e, ou, renda (ou produção) dos setores básicos e $E_{n b}$, nível de atividade, é medido também pelo emprego e, ou, pela renda (ou produção) nos setores não-básicos.

A idéia principal do exposto e que, na literatura, é conhecida como análise do multiplicador da base é que as atividades classificadas como exportadoras são, com efeito, a razão de ser de determinada região econômica, ou seja, formam a sua base econômica. As outras atividades "que não são da base" originam-se desta e crescem ou se retraem, dependendo do desempenho da base. Assim, um aumento na demanda externa dos produtos e serviços exportáveis pode proporcionar um efeito positivo na renda da economia da região e, portanto, aumentar a demanda dos produtos e serviços não-exportáveis. Já o setor exportador produz em resposta às demandas exógenas ou externas. 
O modelo de base econômica, em sua forma original, é estático e orientado pela demanda, visto que não leva em consideração os fatores que modificam a oferta regional de produtos e outros fatores que poderiam afetar a demanda, como, por exemplo, a introdução de novos produtos. Logo, no referido modelo, as atividades não-básicas são dependentes das básicas, como mostrado na equação (2.2).

$E_{n b}=f\left(E_{b}\right)=\alpha+\beta E_{b}$.

Ao combinar as equações (2.1) e (2.2), verifica-se, de forma explícita, a dependência da atividade econômica em relação às atividades básicas. Assim,

$\mathrm{E}_{\mathrm{t}}=\alpha+(1+\beta) \mathrm{E}_{\mathrm{b}}$.

A expressão $(1+\beta)$ é o multiplicador de base econômica, que é formado pelo impacto inicial no setor básico (1) mais a razão de base econômica $(\beta)$, que é a razão entre o emprego nas atividades não-básicas e o emprego nas básicas.

Destaca-se ainda que, na sua forma original, o modelo admite que não haja restrição à oferta de fatores produtivos (e.g insumos necessários para produzir bens e serviços). Em outras palavras, no modelo considerase a oferta de fatores produtivos como perfeitamente elástica (Malecki, 1991).

Segundo Malecki (1991), uma das vantagens do modelo de base econômica é que ele proporciona respostas simples e tem pequena necessidade de informação, no que se refere à análise da economia regional e à estimação dos impactos dos ganhos e perdas da atividade básica. Já para Richardson (1973), a contribuição do modelo de base econômica centra-se na ênfase dada ao grau de abertura das economias regionais e no papel desempenhado pelas mudanças no padrão de demanda 
externa à região, no crescimento econômico regional.

No que tange às interações presentes no modelo, pode-se afirmar que a formulação original do modelo capta a dependência do setor básico em relação ao não-básico (dependência setorial das exportações), entretanto, não é possível captar a dependência espacial, ou seja, a interdependência das regiões.

Segundo North (1977), o sucesso da base de exportação tem sido o fator determinante da taxa de crescimento das regiões. Portanto, para entender o crescimento regional é necessário examinar os fatores que propiciam o desenvolvimento dos produtos básicos de determinada região.

É importante ressaltar que o processo de crescimento de determinada região depende tanto dos condicionantes internos à região (i.e., elasticidade-renda dos produtos, diversificação produtiva, desenvolvimento dos transportes e melhorias no custo de processamento) quanto dos condicionantes externos (i.e., variações de renda, desenvolvimento dos transportes e mudança de gostos). Portanto, a análise da produção de café, sob a ótica espacial, é de suma importância, pois o desenvolvimento dos transportes e as melhorias no custo de produção e processamento, quando existentes também na vizinhança,podem potencializar a aglomeração produtiva.

Segundo North (1977), a formação da base de exportação está altamente correlacionada com a produção de produtos agrícolas. Todavia, esse autor afirma que, para haver indução ao processo de urbanização, aperfeiçoamentos do mercado de fatores e alocação mais eficiente dos recursos para investimento, faz-se necessário que a exportação agrícola seja bem sucedida.

Schwartzman (1975) reforça as idéias de North (1977), ao afirmar que o desenvolvimento de determinada região, centrado na base de exportação, depende do grau de dinamismo da base e da difusão desta para os demais setores da economia regional. Em síntese, faz-se necessário que ocorra a manutenção do dinamismo do produto que forma 
a base de exportação e que haja difusão do dinamismo para outros setores da economia.

\section{Metodologia e tratamento dos dados}

\subsection{Base de dados}

$\mathrm{Na}$ elaboração do banco de dados foi utilizada a Pesquisa Agrícola Municipal (PAM), obtida junto ao IBGE pelo sistema SIDRA (Sistema IBGE de Recuperação Automática), o qual se refere às 558 microrregiões brasileiras, durante o período de 1991 a 2003. Como os dados de 1991 a $2000^{6}$ estavam despadronizados, foi necessária a conversão destes para toneladas. Com o intuito de conferir maior consistência ao modelo, foram retiradas da análise todas as microrregiões que apresentaram produção igual a zero (exceto na análise do Moran bivariado) ${ }^{7}$.

Este trabalho faz uso de variáveis relativas em sua análise. As variáveis extensivas ou absolutas podem levar a engano na interpretação dos resultados, pois costumam estar correlacionadas com o tamanho da população ou com a área das regiões em estudo. Assim, com vistas em implementar a análise de dados espaciais, identificar regimes espaciais ou clusters para a produção de café e verificar sua dinâmica no decorrer dos anos em estudo, foram construídos indicadores de concentração da produção do café para cada uma das 558 microrregiões do Brasil.

\subsection{Medida de concentração}

O indicador de concentração utilizado neste trabalho é o Quociente Locacional (QL), que é uma medida de especialização, pois compara o setor (i.e., produção de café) de determinada região com o mesmo setor,

Dados do período de 2001 a 2003 já estão disponíveis, em toneladas, no sistema SIDRA IBGE.

7 Na análise do Moran bivariado são consideradas todas as microrregiões, já que esta é uma análise temporal e necessita de um número igual de microrregiões nos anos em questão para ser efetuada. Mais detalhes sobre o Moran bivariado serão discutidos na seção 3.3.3. 
na região de referência (i.e., estado, país ou outra região). Em outras palavras, o QL compara duas estruturas setoriais-espaciais e é dado pela razão entre duas estruturas econômicas: no numerador tem-se a economia em estudo e no denominador, a economia de referência.

Este indicador tem sido utilizado em trabalhos exploratórios para mensurar a atividade exportadora da região e, segundo Haddad et al. (1985), é medido da seguinte forma:

$$
Q L=\frac{E^{i}{ }_{j} / E_{j}}{E_{B R}^{i} / E_{B R}},
$$

em que $E^{i}{ }_{j}$ é produção da commodity i, na região j; $E_{j}$, produção agrícola total, na região j; $E_{B R}^{i}$, produção da commodity i, no Brasil; e $E_{B R}$, produção agrícola total, no Brasil.

Segundo Haddad et al. (1985 p. 232), se o valor do quociente for maior do que 1, isto significa que a região é relativamente mais importante, no contexto nacional, em termos do setor, do que em termos gerais de todos os setores. Isso implica dizer que um quociente locacional acima da unidade poderia indicar que a atividade inerente ao setor, na região em análise, é uma atividade básica, ou seja, voltada para a exportação e satisfaz a demandas de fora da região, ou seja, são classificadas como a base de exportação da região $\left(E_{b}\right)$. Por outro lado, um quociente menor do que um representaria uma atividade não-básica, ou seja, a produção setorial seria voltada para a própria região, ou seja, são atividades que são fornecedoras, principalmente, de produtos e serviços aos residentes locais $\left(E_{n b}\right)$. 
Segundo Crocco et al. (2003), o indicador é capaz de captar algumas características importantes, como a especificidade de um setor dentro de uma região, o seu peso em relação à estrutura produtiva da região e a sua importância a nível nacional ${ }^{8}$.

\subsection{Análise espacial}

Com a finalidade de analisar a distribuição espacial do café no Brasil e, assim, tentar identificar algum tipo de cluster (e.g., aglomeração produtiva), é utilizada a análise exploratória dos dados espaciais (AEDE), que está baseada nos aspectos espaciais da base de dados. Segundo Gonçalves (2005, p. 11), a análise exploratória de dados espaciais é útil para descrever distribuições espaciais, revelando padrões espaciais (clusters espaciais), regimes espaciais ou outras formas de instabilidade espacial (não-estacionariedade) e observações atípicas (outliers). De acordo com Anselin (1998), há possibilidade de extrair medidas de autocorrelação espacial e local por meio deste método.

Portanto, após a obtenção do indicador de concentração produtiva para cada uma das microrregiões brasileiras, é possível descrever a distribuição espacial do setor em estudo, por meio da implementação da análise exploratória de dados espaciais.

\subsubsection{Autocorrelação espacial global}

Segundo Anselin (1995), para calcular a autocorrelação espacial é usado o $I$, de Moran, que é determinado pela seguinte equação:

8 Negrito do autor. 


$$
I_{t}=\left(\frac{n}{S_{o}}\right)\left(\frac{z_{t}^{\prime} W z_{t}}{z_{t}^{\prime} z_{t}}\right) t=1, \ldots n
$$

em que $z_{t}$ é o vetor de $n$ observações para o ano $t$, na forma de desvio em relação à média; $W$, matriz de pesos espaciais, em que os elementos $w_{i j}$ indicam a forma como a região $i$ está espacialmente conectada com a região $j$; e o termo $S_{o}$ é um escalar igual à soma de todos os elementos de $W$.

Quando há normalização na linha da matriz de pesos espaciais, em outras palavras, quando $n=$, tem-se:

$$
I_{t}=\left(\frac{z_{t}^{\prime} W z_{t}}{z_{t}^{\prime} z_{t}}\right) t=1, \ldots n
$$

De acordo com Gonçalves (2005), o I, de Moran, revela a tendência geral de agrupamento de dados, caracterizando, assim, uma medida global. Portanto, este indicador é ineficaz para revelar padrões locais de associação espacial, ou seja, a estrutura regional de autocorrelação espacial.

\subsubsection{Autocorrelação espacial local}

Para verificar a correlação espacial local, faz-se necessário o uso de outras três ferramentas, que são o diagrama de dispersão, de Moran; o mapa de clusters; e os indicadores locais de associação espacial (LISA).

O diagrama de dispersão, de Moran, segundo Anselin (1995), identifica a tendência geral de associação por meio da correlação linear entre $W z$, que são os valores da variável de interesse defasados espacialmente, e $z$, que são os valores observados em cada unidade espacial. 
O diagrama também apresenta as tendências locais, que são representadas por cada ponto do interior deste. Pelo diagrama é possível observar valores discrepantes (outliers), que são pontos distantes em relação à tendência central, ou seja, destoantes em relação às outras observações. A análise do diagrama também possibilita a observação de pontos de alavancagem (leverage points ${ }^{9}$ ), que são os pontos que exercem grande influência na tendência central.

Segundo Anselin (1995), o diagrama de dispersão, de Moran, é dividido em quatro quadrantes ${ }^{10}$, que correspondem a quatro padrões diferentes e possibilitam classificar as associações espaciais entre as microrregiões e seus respectivos vizinhos.

As microrregiões que apresentam padrões AA e BB têm associação espacial positiva e formam clusters de valores similares, e as que apresentam padrões BA e AB, associação espacial negativa.

Com vistas em melhor visualizar os quatro quadrantes do gráfico de dispersão, é utilizado, neste trabalho, o mapa de clusters.

Os indicadores LISA são usados para indicar a medida do grau de significância do agrupamento espacial. A soma destes indicadores, para todas as microrregiões, é proporcional ao indicador de autocorrelação de espaço global, o qual é representado pela seguinte expressão:

\footnotetext{
Segundo Varga (1998), se a reta de regressão apresentar inclinação positiva, os pontos localizados a mais de dois desvios-padrões do centro, nos quadrantes superior direito e no inferior esquerdo, são classificados como pontos de alavancagem. Para identificar os valores discrepantes utilizar-se-á, neste trabalho, a distância de cook.

${ }^{10}$ Primeiro quadrante: localiza-se no canto superior direito e é chamado de padrão Alto-Alto (AA). Caracterizase por microrregiões que apresentam elevados valores para a variável em análise, circundadas por vizinhos que também possuem elevados valores para a mesma variável; - Segundo quadrante: localiza-se no canto superior esquerdo e é chamado de padrão Baixo-Alto (BA). Caracteriza-se por microrregiões que apresentam baixos valores e são circundadas por vizinhos que apresentam elevados valores; - Terceiro quadrante: localiza-se no canto inferior esquerdo e é chamado de padrão Baixo-Baixo (BB). Caracteriza-se por microrregiões que apresentam baixos valores e são circundadas por vizinhos que também apresentam baixos valores; - Quarto quadrante: localiza-se no canto inferior direito e é chamado de padrão Alto-Baixo (AB). Caracteriza-se por microrregiões que apresentam elevados valores e são circundadas por vizinhos que apresentam baixos valores.
} 


$$
I_{i, t}=\frac{\left(x_{i, t}-\mu_{t}\right)}{m_{o}} \sum_{j} w_{i j}\left(x_{j, t}-\mu_{t}\right) \operatorname{com} m_{o}=\frac{\left(x_{i, t}-\mu_{t}\right)^{2}}{n},
$$

em que é a observação de uma variável de interesse, na região $i$ e no ano $t ; \mu$, média das observações entre as regiões, no ano $t$; e, para o cálculo de $j$, somente os valores vizinhos mais próximos são incluídos.

É importante ressaltar que, neste estudo, os cálculos do $I$, de Moran, e do LISA são feitos apenas para as regiões produtoras da commodity em estudo, para que não haja possibilidade de a quantidade de números de zeros diminuir o valor médio e aumentar os agrupamentos de valores alto, já que essas estatísticas são calculadas a partir da soma das diferenças entre cada valor observado e a média dos valores observados ${ }^{11}$.

\subsubsection{Análise Espacial Temporal}

Segundo Perobelli e Haddad (2005), pelo uso do diagrama de dispersão bivariado, é possível analisar a autocorrelação espacial em determinado espaço de tempo. Este diagrama é formado por duas variáveis iguais, que, neste trabalho, são o quociente locacional da produção de café, mensurado em diferentes períodos. A autocorrelação espacial temporal é medida da seguinte maneira:

$$
I_{t-s}=\left(\frac{n}{S_{o}}\right)\left(\frac{z_{t}^{\prime} W z_{t}}{z_{t}^{\prime} z_{t}}\right) t=1, \ldots n
$$

\footnotetext{
$\overline{11}$ Este procedimento foi implementado por Varga (1998) e Gonçalves (2005).
} 


\subsubsection{Determinação da Matriz de Pesos Espaciais ${ }^{12}$}

De acordo com Perobelli et al. (2005, p. 7), a matriz de pesos é a forma de expressar a estrutura espacial dos dados e é o ponto inicial para qualquer teste estatístico ou modelo. Há possibilidade de se trabalhar com grande número de matrizes de peso dispostas na literatura. Neste trabalho, a matriz de pesos espaciais é baseada na idéia dos $k$ vizinhos mais próximos, em que é utilizada a idéia de grande círculo entre os centros das regiões.

Segundo Perobelli et al. (2005), a forma da matriz de pesos espaciais é a seguinte:

$$
\left\{\begin{array}{l}
w_{i j}(k)=0 \text { se } i=j \\
w_{i j}(k)=1 \text { se } d_{i j} \leq D_{i}(k) \text { e } w_{i j}^{*}(k)=w_{i j}(k) / \sum_{j} w_{i j}(k) \text { para } k=1,2, \ldots, n \\
w_{i j}(k)=0 \text { se } d_{i j}>D_{i}(k)
\end{array}\right.
$$

em que $d_{i j}$ é a distância, medida pelo grande círculo, entre os centros da regiões $i$ e $j ; D_{i}(k)$, valor crítico que define o valor de corte, ou seja a distância máxima para considerar regiões vizinhas à região $i$.

\section{Resultados e discussão}

\subsubsection{Estatística I, de Moran}

Ao verificar a evolução do $I$, de Moran, para os 15 vizinhos mais próximos, em relação ao quociente locacional do café (ver Tabela 1), observa-se que, no decorrer dos anos, não há tendência de crescimento em todo o

\footnotetext{
${ }_{12}$ Para verificar a robustez dos resultados, são utilizados, neste trabalho, valores para $\mathrm{k}$ iguais a 15,20 e 25 , o que pode ser visualizado, sob consulta, na análise de robustez realizada para cada commodity.
} 
período da análise. Nos anos de 1991 a 1997, há elevação, o que equivale a dizer que, neste período, a produção de café concentrou-se mais em termos espaciais. Entretanto, essa tendência sofreu pequena queda no ano de 2003. Tal concentração pode ser devida, em parte, aos fatores que propiciam o desenvolvimento dos produtos básicos de determinada região, ou seja, aos condicionantes internos da região (i,e., elasticidaderenda dos produtos, desenvolvimento dos transportes, melhorias no custo de processamento).

Tabela 1 - Indicador Global de Autocorrelação Espacial para o QL (1991- 1997 - 2003)

\begin{tabular}{ccccc}
\hline Ano & I de Moran & Média & Desvio-Padrão & $\mathrm{Z}$ \\
\hline 1991 & 0.3067 & -0.003 & 0.004892 & 63.3074 \\
1997 & 0.3447 & -0.003 & 0.004851 & 71.6759 \\
\hline 2003 & 0.3413 & -0.003 & 0.004827 & 71.5351 \\
\hline
\end{tabular}

Fonte: elaboração própria com base no programa SpaceStat ${ }^{\mathrm{TM}}$.

\subsubsection{Diagrama de Dispersão, de Moran (Moran Scaterplot)}

Pelo Diagrama de Dispersão, de Moran (Figura 1), é possível: a) Identificar a presença dos quatro tipos de regimes espaciais na produção de café no país, no decorrer dos anos analisados; b) Verificar que, no ano de 1991, $72,24 \%$ das microrregiões tiveram correlação espacial positiva, sendo que $15,05 \%$ do total estavam no quadrante AA do diagrama e 57,70\% do total localizava-se no quadrante BB, do diagrama; c) Observar que, no ano de 1997, este índice aumentou, chegando a representar 72,32\% das microrregiões; e d) Constatar que, no ano de 2003, este índice aumentou ainda mais, chegando a atingir 79,37\% das microrregiões produtoras de café do país.

É possível perceber que as microrregiões de Alegre (ES) e Manhuaçu (MG) possuem um QL básico voltado para exportação. Essas microrregiões constituem dois pontos de fronteira no diagrama de 
dispersão, fato que influencia, negativamente, a reta de regressão, diminuindo o $I$, de Moran. Se retirar essas microrregiões da análise, o $I$, de Moran, passaria a ser de 0,3292, 0,4012 e de 0,3959, respectivamente, nos anos de 1991, 1997 e 2003.

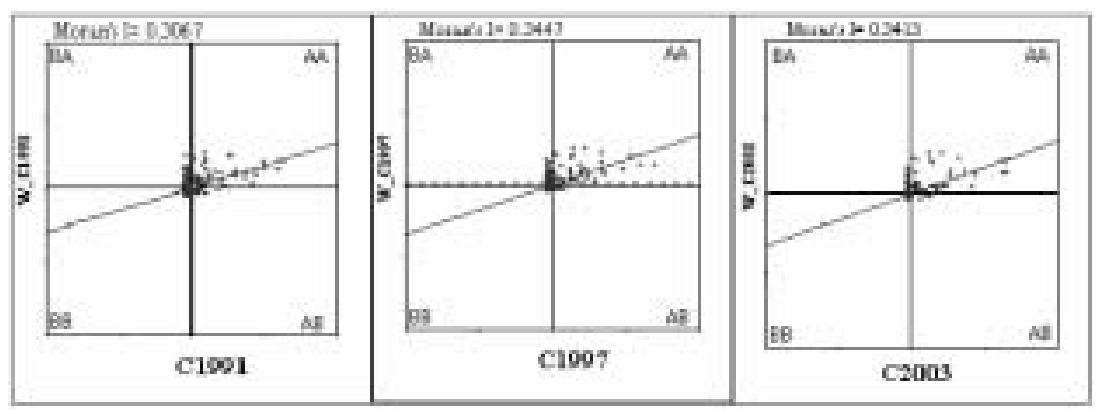

Figura 1- Diagrama de Dispersão, de Moran (1991, 1997 e 2003)

Nota: C1991, C1997 e C2003 = quociente locacional para café, nos anos de 1991, 1997 e 2003.

W_C1991, W_C1997 e W_C2003 = defasagem espacial do quociente locacional para o café, nos anos 1991, 1997 e 2003.

Fonte: elaboração própria com base no programa GeoDA.

Em todos os anos analisados, as microrregiões de Alegre (ES) e Manhuaçu (MG) demonstraram ter grande importância, já que, junto com outras microrregiões influentes de padrão AA, como Santa Teresa (ES) e Campo Belo (ES), estão espacialmente agrupadas e formam um cluster de alta potencialidade local.

\subsubsection{Mapas de Dispersão, de Moran}

A análise dos mapas de dispersão, de Moran (Figuras 2 e 3), permite afirmar que, nos anos de 1991 e de 1997, houve notável presença do padrão $\mathrm{AB}$ em algumas microrregiões dos estados do Paraná e de São Paulo (e.g., Umuarama e Paranavaí, no Paraná, e Marília e Jales, em 
São Paulo). Entretanto, em 2003, essas microrregiões apresentaram padrão BB (Figura 3), o que equivale a dizer que suas microrregiões vizinhas as influenciaram negativamente no que diz respeito ao QL de café. No total, no ano de 1991, havia 15 microrregiões de padrão AB e no ano de 2003, apenas 6.
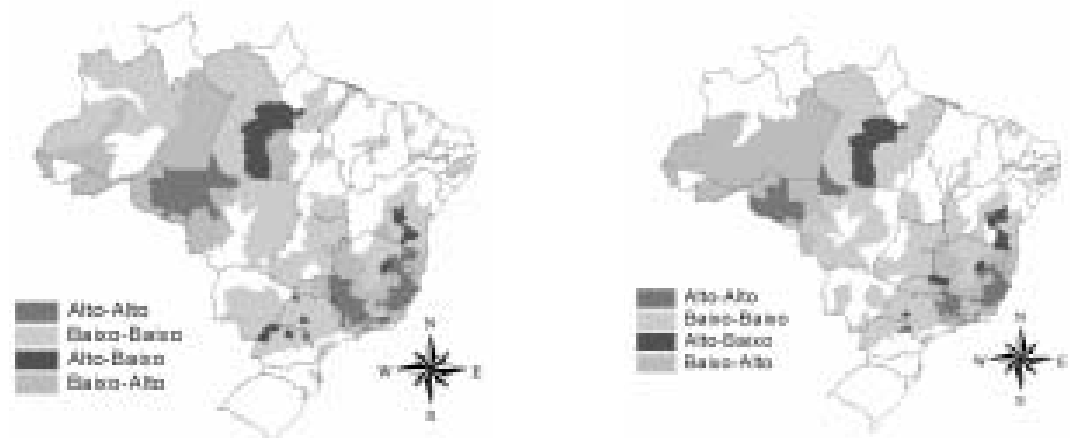

Figura 2 - Mapa de dispersão, de Moran, para QL de café (1991 e 1997) Fonte: elaboração própria com base no programa ArcView.

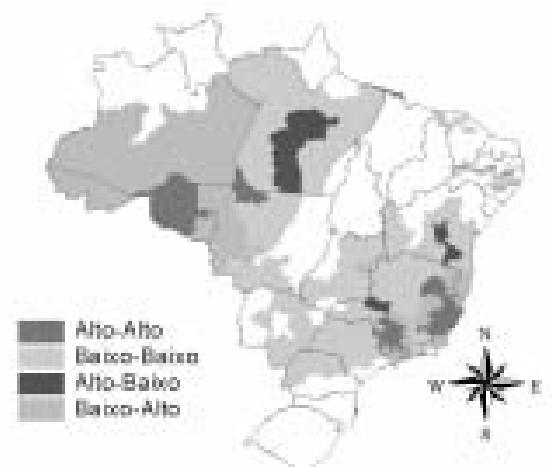

Figura 3 - Mapa de dispersão, de Moran, para QL de café em 2003 Fonte: elaboração própria com base no programa ArcView. 
É importante destacar que todas as microrregiões que compõem os clusters citados são básicas, cuja produção é voltada para exportação, e são relativamente mais importantes no contexto nacional, em relação ao café, do que em termos gerais de todos os setores agrícolas, devido ao fato de terem quocientes locacionais maiores que um. No caso das microrregiões do estado de Rondônia e do Mato Grosso, em especial, estes QLs são muito maiores que um, chegando a alcançar valores superiores a 100 , em determinados momentos.

No ano de 2003 (ver Figura 3), os clusters de regime AA para o QL de café, no Brasil, estavam em grande parte do estado de Rondônia (microrregiões de Alvorada, Cacoal, Ji-Paraná, Ariquemes e Porto Velho; na microrregião de Alta Floresta no Estado de Mato Grosso; em grande parte do estado do Espírito Santo e em algumas microrregiões da parte leste do estado de Minas Gerais; e em microrregiões da parte Sul do estado de Minas Gerais.

\subsubsection{Indicadores Locais de Associação Espacial (LISA)}

O número de microrregiões que está nos quadrantes de associação espacial positiva diminuiu ao longo dos anos, visto que passou de 26 , em 1991, para 25, em 1997, e para 22, em 2003 (Figuras 4 a 6). Sua porcentagem, em relação às microrregiões significantes, aumentou no ano de 1997 e diminuiu no de 2003 (de 89,66\%, em 1991, para 89,29\%, em 1997, e para 88\%, em 2003). É importante destacar que essa porcentagem se deve apenas às microrregiões que se encontram no quadrante $\mathrm{AA}$, pois as microrregiões de padrão $\mathrm{BB}$ não são significantes a $0,5 \%$, fato que também acontece nas microrregiões de padrão $\mathrm{AB}$. As microrregiões com maiores níveis de significância são de regime AA e que possuem QL maior que 1.

Uma questão importante a ser observada é que as microrregiões de níveis de significância de $0,1 \%$ se encontram nos estados de Minas Gerais e do Espírito Santo, que, segundo SIDRA (2006), eram responsáveis por 
$56,90 \%$ da produção nacional de café, no ano de 1991, e que, com o passar dos anos, elevaram sua participação no contexto nacional e, no ano de 2004 , foram responsáveis por $70,66 \%$ da produção nacional de café.
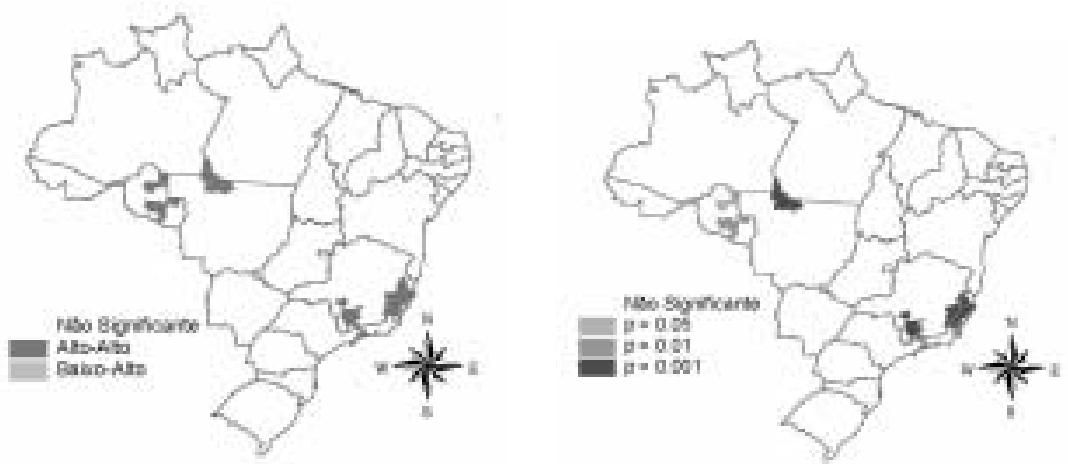

Figura 4 - Mapa de Clusters para QL de Caté, em 1991

Fonte: elaboração própria com base no programa ArcView.
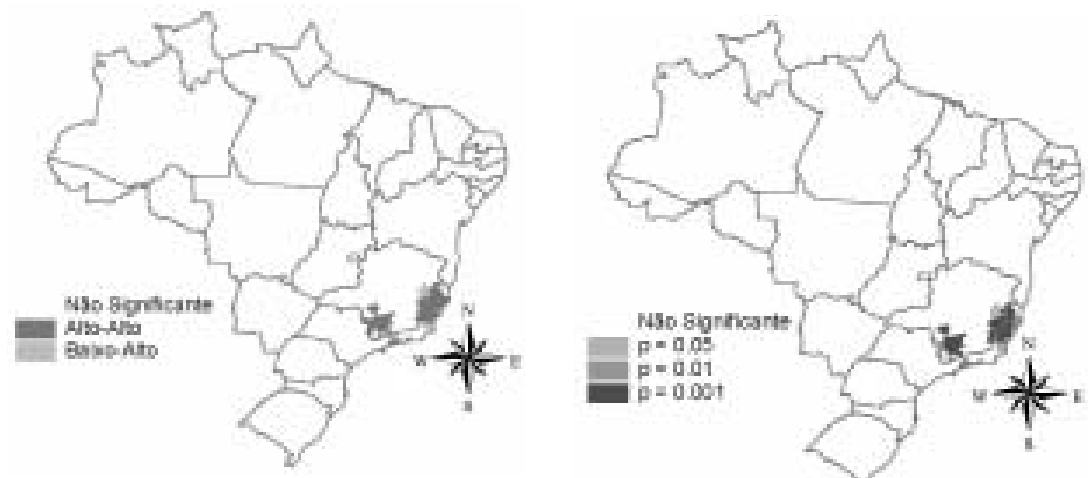

Figura 5 - Mapa de Clusters para QL de Café, em 1997

Fonte: elaboração própria com base no programa ArcView. 

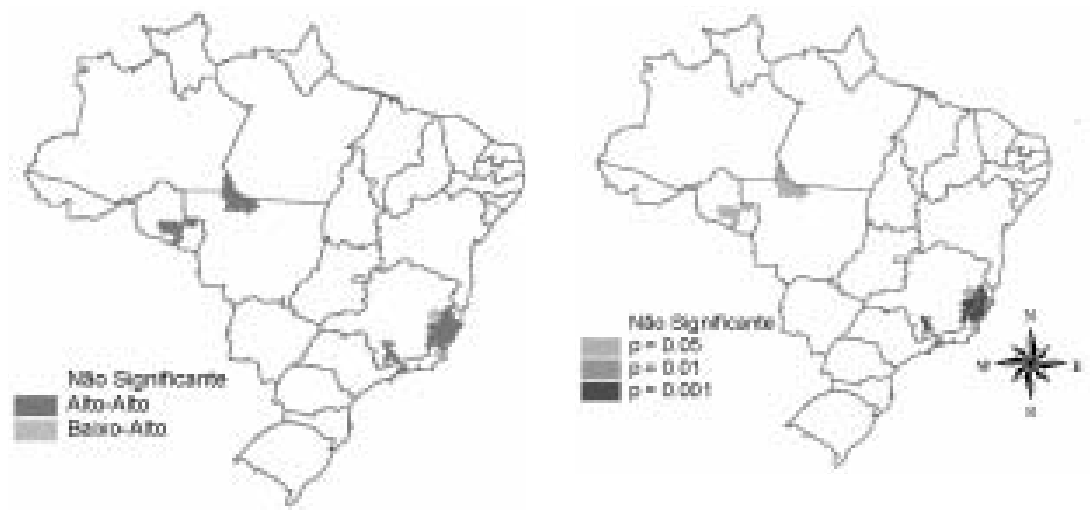

Figura 6 - Mapa de Clusters para QL de Café, em 2003

Fonte: elaboração própria com base no programa ArcView.

\subsubsection{Mapa de Clusters, de Moran, Bivariado}

Pelos mapas de clusters bivariados (Figuras 7, 8 e 9), é possível visualizar, por exemplo, na Figura 9, a presença de microrregiões nos estados de São Paulo, Minas Gerais e Rondônia, que tiveram padrão AA no ano de 1997 e foram circundadas por microrregiões de padrão AA no ano de 2003.

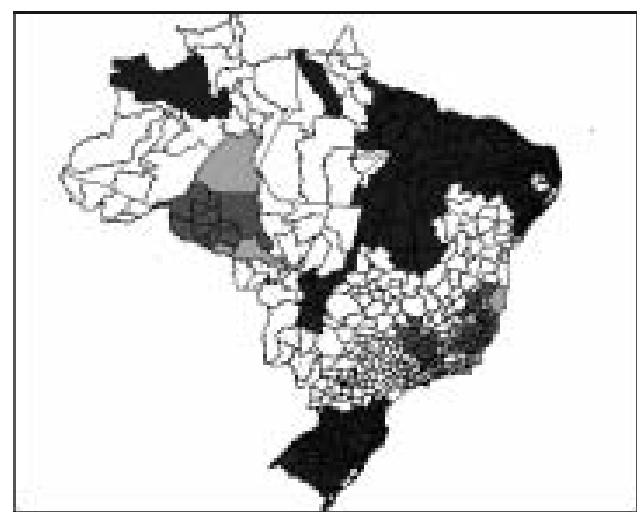

Figura 7 - Mapa de Clusters Bivariado: 1991 e 1997 


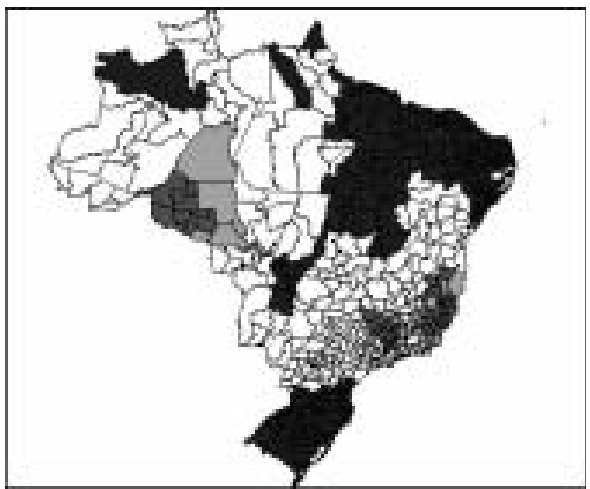

Figura 8 - Mapa de Clusters Bivariado: 1991 e 2003

Nota: a cor vermelha representa os clusters AA; a cor azul, os clusters $\mathrm{BB}$; a cor roxa; os clusters BA; e a cor rosa, os clusters AB.

Fonte: elaboração própria com base no programa GeoDA.

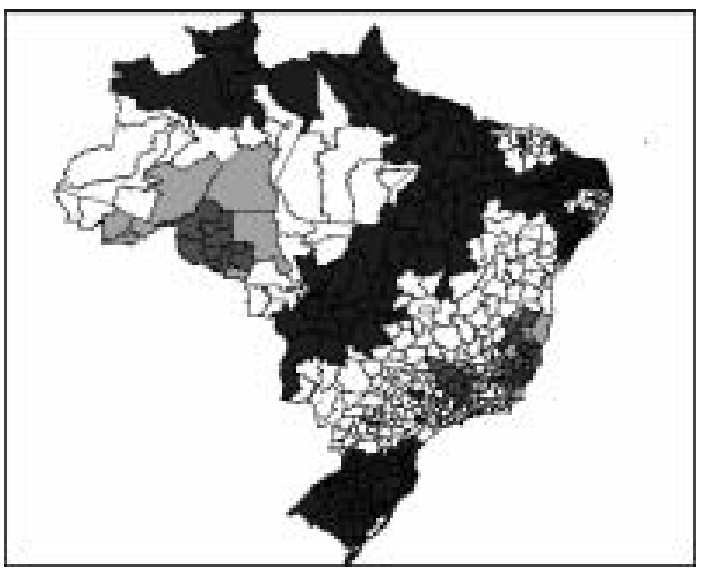

Figura 9 - Mapa de Clusters Bivariado: 1997 e 2003

Nota: a cor vermelha representa os clusters AA; a cor azul, os clusters BB; a cor roxa, os clusters $\mathrm{BA}$; e a cor rosa, os clusters $\mathrm{AB}$.

Fonte: elaboração própria com base no programa GeoDA. 
Os clusters formados por essas microrregiões demonstram ter certa estabilidade espacial ao longo de todo o período analisado, o que confirma que a estrutura espacial de produção do café se mantém espacialmente concentrada. Este resultado mostra a especificidade do setor dentro das regiões, o seu peso em relação à estrutura produtiva das regiões e a sua importância em nível nacional.

\section{Conclusões}

A aplicação da AEDE permitiu verificar a presença de correlação espacial positiva entre as microrregiões do país, no decorrer dos anos analisados, para o quociente locacional do café. Este estudo foi importante devido ao fato de ter possibilitado a identificação de clusters de regiões produtoras locais e para o mercado externo às microrregiões e, assim, contribuir para melhor entender a distribuição territorial do café.

Dentre estes resultados, é observar que:

a) A correlação espacial, com relação ao café, foi maior no ano de 2003, em relação ao índice encontrado no ano de 1991. É possível destacar que a estrutura espacial de produção do café persiste espacialmente concentrada, principalmente nos estados de Minas Gerais e Espírito Santo, que, em 2004 , representaram $70,66 \%$ da produção nacional do café, e em microrregiões do estado de Rondônia, que apresentaram quocientes locacionais muito elevados para produção desse produto. Estes quocientes locacionais são elevados devido ao fato de a cafeicultura ser uma das mais importantes atividades econômica e social do estado de Rondônia, empregando mais de 80.000 pessoas e de cujo sucesso depende 44.000 famílias (Neto apud CARTA..., 2002).

b) Pela análise dos mapas de dispersão bivariados para o café, verificouse certa estabilidade espacial, o que confirma a persistência dos clusters de regime AA, ao longo do tempo. 
Portanto, o trabalho realizado tem grande importância para os formuladores de política regional, já que comprova o fato de que microrregiões brasileiras que possuem elevada concentração de produção do café, vizinhas de microrregiões que também possuem elevada concentração de produção para a mesma commodity, têm grandes chances de persistirem com elevada produção ao longo do tempo, além de concentrar e formar importantes clusters produtores. É importante destacar que microrregiões de elevada produção, vizinhas de microrregiões de baixa produção, tendem a ter baixa produção no futuro. Em outras palavras, os formuladores de desenvolvimento regional podem, por meio deste estudo, identificar quais as regiões que têm, na produção de café, um potencial latente para o seu desenvolvimento.

Em outras palavras, a formação de clusters AA em regiões classificadas como básicas (dentro do contexto nacional e comparado com os demais produtos do setor agrícola) e, portanto, que satisfazem às demandas de fora da região indica que aumento na demanda de café pode proporcionar efeitos positivos nessas regiões. A importância do estudo espaço-temporal da produção do café visa, portanto, explicitar que tal atividade pode ser um fator determinante do crescimento deste conjunto nessas regiões (e.g., aglomeração espacial).

Como uma extensão futura para este trabalho, é possível implementar um teste econométrico, com a finalidade de analisar a convergência das microrregiões para a produção de café, ou seja, se as microrregiões de baixa produção tendem a atingir níveis de produção similares às principais microrregiões produtoras. 


\section{Referências}

ANSELIN, L. Local indicators of spatial association - LISA. Geographical Analysis. V 27 (2), April. p 93-115. 1995.

ANSELIN, L. Interactive techniques and exploratory spatial data analisys. Longley P. A, Goodchild M.F, Maguire D.J and Wind D. W (eds). Geographical information system: principles, techniques, management and applications. Wiley: New York. 1998. p 253-365.

CARTA DE JI-PARANÁ, RONDÔNIA, BRASIL. Caminhos para a revitalização do agronegócio do café na Amazônia. In: Seminário Internacional do Agronegócio Café na Amazônia, 1, 2002. Ji-Paraná. Anais... Ji-Paraná: Embrapa, IICA/PROCITRÓPICOS.

CROCCO, M. A.; GALINARI, R.; SANTOS, F.; LEMOS, M. B.; SIMÕES, R. Metodologia de Identificação de Arranjos Produtivos Locais Potenciais: Uma Nota Técnica. Texto para discussão CEDEPLAR N 191, Belo Horizonte: UFMG, 2003. 12 p.

FUGITA, M; KRUGMAN, P e VENABLES, A.J. Economia Espacial: urbanização, prosperidade econômica e desenvolvimento humano no mundo. MIT, 1999.

GOMES, M.F.M e ROSADO, P.L. Mudança na produtividade dos fatores de produção da cafeicultura nas principais regiões produtoras do Brasil. Revista de Economia e Sociologia Rural. V. 43. n.4. Brasília out/dez 2005.

GONÇALVES, E. A Distribuição Espacial da Atividade Inovadora Brasileira: Uma Análise Exploratória. Texto para discussão CEDEPLAR N ${ }^{\circ}$ 246, Belo Horizonte: UFMG, 2005. 33p.

HADDAD P. R. Economia Regional: Teoria e Métodos de Análise. BNB. Fortaleza, 1985. 
MALECKI, E. J (1991). Technology and economic development: the dynamics of local, regional, and national change. Longman.

NORTH, D.C. A agricultura no crescimento econômico regional. In: SCHWARTZMAN, J (org). Economia regional: textos escolhidos. Belo Horizonte: CEDEPLAR/MINTER, p. 333-343. 1977.

Perobelli, F. S. ; HADDAD, E. A. Padrões de Comércio Interestadual no Brasil: 1985 e 1997. Revista de economia contemporânea, Rio de Janeiro, v. 10, n. 1, 2006.

PEROBELLI, F. S; ALMEIDA, E. S; ALVIM, M. I. S; FERREIRA, P. G. C. Análise Espacial da Produtividade do Setor Agrícola Brasileiro: 1991 - 2003. Juiz de Fora: UFJF/Faculdade de Economia e de Administração, 26 p., 2005. (Texto para discussão: 19).

RICHARDSON, H.W. Regional growth theory. New York, Wiley. 1973

RUGANI, F. do L e SILVEIRA, S. de F. R. Análise de Risco para o café em Minas Gerais. Revista de Economia e Agronegócio, Viçosa, v. 4, n. 3, p 343-364. 2006.

SANTOS, V.E; GOMES, M.T.M e GOMES, M.F.M. Estimativa da elasticidade-renda do consumo de café na região Sudeste do Brasil. Revista de Economia e Agronegócio, Viçosa, v. 3, n. 4, p 537-558. 2005.

SCHWARTZMAN, J. Teoria da base de exportação e o desenvolvimento regional. In: HADDAD, P.R. Desequilíbrios regionais e descentralização industrial. Monografia 16. Rio de Janeiro. IPEA/ IPLAN, 1975.

SEAG. Secretaria de Estado da Agricultura, Abastecimento, Agricultura e Pesca (ES). Vitória, 2006. Disponível em : < http:// www.seag.es.gov.br/> Acesso em: 4 jan 2006. 
SIDRA. Sistema IBGE de Recuperação Automática. Brasília, 2005. Disponível em: < http://www.sidra.ibge.gov.br/bda/ > Acesso em: 5 fev 2005.

SIDRA. Sistema IBGE de Recuperação Automática. Brasília, 2006. Disponível em: < http://www.sidra.ibge.gov.br/bda/ > Acesso em: 4 jan 2006.

\section{VARGA, A. University research and regional innovation: a spatial econometric analysis of academic technology transfers. Boston/ Dordrecht/London: Kluwer Academic Publishers, 1998.}

VALE, S.M.L.R do; TEIXEIRA, M.B e SANT'ANNA, J.C.O. Estilos gerenciais e eficácia administrativa na produção de café. Revista de Economia e Agronegócio, Viçosa, v. 4, n. 4, p 533-552. 2006.

Abstract - The study of the spatial distribution of the production of coffee between the 558 micro Brazilian regions is the main aim of this paper. The research is for the period 1991 to 2003. This paper enables us to identify spatial regimes and clusters for coffee's production and also it's dynamic during the period. To reach the objective we use the idea of locational quotient to measure the concentration in the production of coffee and also the exploratory spatial data analysis. It was possible to verify that the spatial structure of production of coffee remains spatially concentrated, mainly at Minas Gerais and Espirito Santo states. Those states represent $70.66 \%$ of total production of coffee. The result for some micro regions located at Rondonia is also important.

Key-words: exploratory spatial data analysis, coffee, export base and locational quotient. 
REVISTA DE ECONOMIA E AGRONEGÓCIO, VOL.5, $N^{o} 3$ 